\title{
Monitoring, Evaluation and Accountability Against Corruption: A South African Case Study
}

\author{
E.A. Mantzaris and P. Pillay
}

ACCERUS, School of Public Leadership, Stellenbosch University, South Africa

\begin{abstract}
The article is an empirical effort to research and analyse the dialectical relationship between public sector monitoring and evaluation relations, structures and processes with corruption and accountability. The case study is the Gauteng Department of Health that has been the subject of this research for the last two years as a part of a wider health-related project.

Following a brief exposition of the concept of monitoring and evaluation that has been covered extensively in international and national literature, its relationship with accountability is explored. The existing legislative national and provincial legislature as well as the existing state rules and regulations are presented before the description of the project's research methods and design. This is a research project utilising a qualitative-based research design and framework consisting of thorough content analysis of primary and secondary sources including government official documents, newspaper articles and face-to-face interviews with a wide range of carefully selected public administrators, political figures and representatives of the public sector. The paper presents an analysis of corruption trends within the department as identified in the latest Auditor General's report, a corruption-ridden case and the wide-ranging responses of the interviewees. The latest evidence-based Corruption Index follows.
\end{abstract}

Keywords: Monitoring and Evaluation, Accountability, Corruption, Gauteng Department of Health.

\section{INTRODUCTION}

Monitoring and Evaluation (M\&E) has been described as a foundation for improved effective and efficient performance within an organisational environment. Its key function is to elevate existing levels of outputs, outcomes and impact to new heights. It is based on performance analysis of programmes and projects undertaken by international organisations, state institutions as well as non-governmental and similar organisations. For a number of years, the process has become a sine qua non of good governance throughout the world and especially developing countries, and has been expanded as important in the private sector (Tarsilla, 2014:2-3).

Monitoring is an oversight process of activities during the implementation stage of a specific or a multiplicity of projects. It consists of well-planned, designed and implemented collection and analysis of data of inputs, outputs, activities and outcomes of a specific project. It takes the form of a continuous assessment process aiming at the provision of detailed, systematic and accurate information to all stakeholders on the progress of the project activities. Evaluation is a process based on a continuous and thorough examination of the efficiency, effectiveness, relevance, and impact of activities that have been based on specific objectives. In this process, errors are isolated

*Address correspondence to this author at the ACCERUS, School of Public Leadership, Stellenbosch University, South Africa; Tel: +27 (0) 21918 4341; Fax: + 27 (0) 21918 4123; E-mail: Pregala@sun.ac.za and/or rectified and lessons are learnt for future endeavours. In this, the impact of success or failure is identified and measured through assessment against its objectives and intended impact (Powell \& DiMaggio, 2012).

Monitoring and evaluation are both integral parts of a cycle. Monitoring is a process of information and data collection that tracks progress and is determined by existing set objectives and terms of reference. Evaluation, on the other hand, is forward-looking and is the application of the lessons and recommendations for future and present projects. Both Monitoring and Evaluation can be utilised in the undertaking of new projects to guide decisions in respect of current and future programmes (Patton, 2011).

In most cases, the credibility of an M\&E programme's assessments and findings relies on the manner in which the process is conducted. In this the rating of targeted outputs and outcomes is key, as success is measured in relation to the baseline of a situation before the project starts and the target at the end of it (Bamberger et al., 2011).

The international literature on M\&E has developed a widely accepted set of principles that determines success or failure, and which begins with 'design' and end with 'follow up', with 'process', 'team selection', 'implementation', 'reporting' and further 'follow up' inbetween).

It has been shown that research-driven planning, when combined with effective monitoring and 
evaluation, is very important in the effectiveness and enhancement of developmental projects and undertakings. Results that matter are based on effective M\&E, as the lessons of the past become integral to the success of the future. Both of these are directly related to the improvement of peoples' lives and choices (United Nations Development Programme Evaluation Office, 2009).

Inevitably, both monitoring and evaluation and their success or failure is based on the accountability levels of those who perform the tasks. This is called 'performance accountability', which is also measured as the processes unfold. Monitoring and evaluation practitioners are responsible for providing their skills and knowledge in order to enable research, comment and judgement on one or more tangible projects through performance tracking analysis and reports to key stakeholders (Feldman \& Pentland, 2003:95-96).

Both monitoring and evaluation are rigorous processes and those performing them are accountable to political and administrative leadership, but also to the citizens and communities they serve. Hence all steps in the process, information data collection and reporting, evaluations, analysis, and reporting, need to be honest, accurate, transparent, accountable and regular (Kusek \& Rist, 2004).

On many occasions the burden of collecting and analysing data in both stages and processes can be extremely detailed, and demand highly professional and scientific knowledge. Hence it can be burdensome. Collection and analysis of data that lead to evaluations and future solutions are founded on measurements, knowledge, rigour, discipline and accountability in order to lead to concrete information on cause and effect at all operational levels (Bamberger et al., 2015).

\section{MONITORING AND EVALUATION LEGISLATION}

The wide-ranging legislative framework for M\&E begins with the Constitution of the country (RSA, 1996) and the White Paper on Transforming Public Service Delivery, 1997 (RSA, 1997). The latter advocates the necessity of strong M\&E systems as the foundation of coordination against the "prevention of fragmentation" (Presidency, 2007:1). The Constitution is the document that significantly equates the basic ethical values of the public sector with accountability and efficient, impartial and equitable service delivery, citizen participation and good human resource management.
The White Paper on Transforming Public Service Delivery is the foundation of the BATHO PELE (People First) principles, where service delivery measures and indicators are determined and evaluated (RSA, 1997).

The Public Finance Management Act (RSA 1999) is rooted on issues of performance monitoring and reporting, and accountability is the foundation of performance excellence as the key characteristic of the ethical and efficient movement from a budget system that is input-based to output that is results-based. In such a system, accountability and M\&E are central to ethical and efficient performance management (Republic of South Africa, 1999: 27-28).

The National Health Act (RSA 2003) set up the parameters for a comprehensive national health system, whereby accountability and M\&E are fundamental (Section 21 9d). It was preceded by the White Paper on Health (1997) and followed by the NHSP (the National Health System Priorities 2009-14), which was considered a 'strategic framework' leading to desired outcomes based on a well-monitored and evaluated Medium Term Strategic Framework (MTSF) and the Millennium Development Goals (MDGs) The key M\&E instrument has been the District Health Information System (DHIS) that is instrumental in research, analysis and monitoring of health services.

The Health Department M\&E structures, functions and processes were outlined in considerable detail in the District Health Management Information System (DEMIS) Policy of 2001 The document assumes that the application of pre-determined standards expected in all of data management activities as well-defined sectional and departmental duties and responsibilities guarantees the integrity, high quality and security of data, is assumed (National Department of Health, 2011:16-18).

The Policy Framework for a Government-wide Monitoring and Evaluation System (GWM\&ES) was adopted officially in 2007 and is based on three fundamentals: social, economic and demographic statistics; performance information, and evaluation (GWM\&ES, 2007: 16-17). Each of these is based on their own policy framework that determines the dynamics of M\&E, which is the foundation of accountability in all spheres of government. It is supplemented by the National Treasury Framework for Managing Programme Performance Information (NTFMPPI), adopted in 2007,, that coordinates all information channels throughout all spheres of government (National Treasury, 2007:1-2). 


\section{Improving Government Performance}

Our Approach, was a key document released by the Presidency in 2009 that outlined the fundamentals of M\&E, supplemented by the MTSG (Medium Term Strategic Framework), a 5-year plan identifying key priorities. It defined ways of monitoring and measuring outputs and inputs, indicators, and activities (Presidency, 2009:3-10).

The National Evaluation Policy Framework (NEPF) was adopted by the government in 2011 and was supplemented by the National Evaluation System (NES) and the the National Evaluation Plan (NEP), set out to improve the existing inconsistency and the performance at all organisation levels throughout the public service spectrum, in terms of increasing accountability, knowledge and capacity. New evaluation systems were introduced throughout the government spectrum. Furthermore, quality assessment tools and improvement plans were introduced in order to elevate evaluation standards and capacity of leaders, managers and M\&E specialists and evaluators (NEPF, 2011:8-15).

The Gauteng Department of Health (GDOH) established an M\&E directorate in 2007 in accordance with the national policy framework and the 2009-2014 5-Year Strategic Plans (the plan referred to covers the period 2009 to 2014). It followed the dictates of existing rules and regulations prioritising the Readiness Assessment, with emphasis on the functions of the existing monitoring, evaluation and reporting systems (Gauteng Department of Health, 2010: 15- 16).

Similar initiatives were introduced in the Gauteng Evaluation Frame and Provincial Evaluation Plan for the Period 2012/2013 to 2015/2016 (Gauteng Planning Commission, 2012).

The processes, structures, outputs and outcomes are measured against the APP (Annual Performance Plan) at both district and provincial levels, and a performance report is generated for the period under investigation.

\section{RESEARCH METHODS}

The case study undertaken to establish the existing relationships of corruption, monitoring, evaluation and accountability in the Gauteng Health Department utilised qualitative methodologies with special emphasis on organisational settings, structures and processes(such as efficiencies, deficiencies, financial and risk management and audit systems ), political oversight, and the existing relationships of institutions and the private sector.

The utilisation of the systems approach was focused on the evaluation of the current status, identifying barriers and facilitators of a policy environment which promotes access to healthcare, and identifying how health policy may be strengthened within the South African context. The same approach was applied in the core framework utilised in guiding the research into the appropriate sociological, legal, political, economic and organizational realities that affect, create and multiply corruption in the public service.

The primary objective of the study in terms of its core questions was to open new paths of understanding of corruption in the various facets of the health sector, utilising a provincial case study. The structuring of the evidence-based Corruption Index sheds light on the phenomenon, common areas and types of corruption, and the organisational environment which invites corruption.

The study aspires to investigate the relationship between existing policies on monitoring, evaluation and accountability through their implementation, as imperatives of practising "good governance", against the backdrop of the organisational and operational contexts in place, the role of leadership and management, and the vulnerability of organisational systems.

The study is rooted on the interpretivist approach and a "subjective ontology" that is based on in-depth interviews, participative action research and cooperative inquiry. The approach is more concerned with information that includes, and is best captured through, words, sentences and narratives, thus setting in motion layers of understanding of how individuals or groups interpret the meanings underlying their experiences (Saunders et al., 2007; Nachmias \& Nachmias, 2008: 195). Understanding and analysing underlying phenomena is crucial (Bryman \& Bell, 2007: $25)$, as the researcher gets closer to the data (Silverman, 2005).

The application of systems theory in combination with the case study method allowed flexibility in the process of data collection, analysis and interpretation (Jankowicz, 2005: 154; Saunders \& Mark, 2007: 25). As the research process unfolds comparisons with 
existing knowledge become inevitable, arising from the interactive process and its temporal, cultural and structural contexts. The researcher is a direct part of what is researched (Sunders \& Mark, 2007: 28; Charmaz 2001).

The study was conducted in Gauteng and purposive sampling was utilised, consisting of 15 interviewees, including seven public servants in the healthcare field, four private sector professionals in the hospital and professions, three academic researchers and experts in the field and one senior political figure.

Unstructured, face-to-face interviews provided the respondent with the opportunity to express herself the way she felt. Participants had the freedom to answer the way they wanted to and were not restricted in their responses. Information corroboration was of vital importance in the exercise (Neuman, 2003: 103104). The interview time fluctuated between one hour, and one hour and thirty minutes. Following each interview, the researcher read the notes to the interviewee verbatim for final verification as a means of checking credibility and authenticity. The researcher thus always sought the confirmation of the participants that their responses, thoughts, attitudes and beliefs, are reflected accurately in the notes and the final draft/s of the report.

The questions gave the participants an opportunity to elaborate on issues pertaining to the way they felt about a variety of problems and challenges facing the healthcare sector and to comment on the multiplicity of relations and actions of all stakeholders and role players. Leading questions, double-barrel questions and ambiguous questions were avoided in this research (Mouth 2010).

The qualitative data obtained was analysed through content analysis, a detailed and systematic examination of the content of conversations with government officials, bureaucrats and senior managers in the private sector, who were interviewed in the context of this study for the purpose of identifying patterns, themes, or biases (Charmaz, 2001).

The evidence-based Index was based principally on de facto and objective indicators, corroborated experience-based indicators, minimal perception-based indicators and input-based indicators (Stemler, 2001; Kimberly, 2002; Krippendorff, 2004).

The Index is based on research covering the last five financial years. It has been compiled through a dissection of key primary official documents such as the SIU annual and comprehensive reports, research and documents produced by the Public Service Commission, the Public Protector, the Auditor General, all relevant documents of the South African Police Service, the National Prosecuting Authority, all documents and reports of the entity under investigation, all reports of the relevant the Parliamentary Monitoring Group (PMA), and 150 newspaper articles, selected through content analysis.

The Index is a record of corruption cases that have been finalised. The 'experience-based evidence' consisted of eight interviews, six with administrative leaders in the sector, one senior politician of the ruling party and one consultant who has worked in the healthcare field for over 5 years.

These were semi-structured interviews with a group of people who have first-hand experience and knowledge around the forms of corruption, and their extent of corruption in the specific work setting, all based on personal knowledge or experience in the past five years. This included knowledge of direct or/and indirect relations of people or groups involved in corrupt acts, including politicians, business people, suppliers, funders, senior or middle managers. They were corroborated with the existing quantitative items and material.

The study deals with sensitive topics, hence it was imperative that it took place within the country's legal parameters and took cognisance of research ethical guidelines, duties and responsibilities. This means that the researchers ensured that they protected the anonymity of participants and did not overstep any whistle-blower laws. Participants' identities were protected and their anonymity was guaranteed. The researchers did not record participants' names in any field notes or other documentation. All efforts to ensure individual anonymity, and how the information would be used, were ensured. The researchers explained this to participants in order to gain properly informed consent to proceed before the commencement of the interviews. The researchers ensured at all times that those interviewed were not uncomfortable with the depth of exploration and discussion.

Voluntary participation is a key principle to adhere to in research. The researchers abided completely by the right to research and acquire knowledge, as well as the rights of individual research participants to selfadministration, privacy and dignity. Hence, through all 
the above measures, anonymity and confidentiality were guaranteed to all interviewees.

The face-to-face interviews were conducted in Gauteng during the last part of 2018.

\section{ANALYSIS OF DATA}

The analysis of data begins with an holistic analysis of the overall situation of the Gauteng Health Department as analysed by the latest Auditor General's report, a case study of fraud and corruption and an analysis of the responses of the carefully chosen interviewees. It is completed by the updated evidencebased Corruption Index for the last five years.

\section{THE AUDITOR GENERAL'S REPORT}

The report of the Auditor General in the last financial year was highly critical of the financial management, internal audit and monitoring and evaluation sections of the Department, as there have been a series of errors at all levels of the financial statements for the year that ended on the 31st of March 2018. In fact, it was discovered that a wide variety of restatement connected to assets was incorrectly omitted or included in the Asset Register (Gauteng Health Department, 2018:143). It was reported in the year's financial statements that the Department had violated Treasury Regulation 8.2.3, as payables worth R3 928108000 exceeded the payment term of 330 days. In addition, this amount exceeded the voted funds by R179 375000 according to the financial statements. Hence, according to the regulations, the amount of R3 748733000 would be classified as unauthorised expenditure, had the amounts due been paid in time (Gauteng Health Department, 2018:144-145).

The Auditor General's report is clear on the fact that the Chapter 9 institution was unable to obtain correct audit evidence on a matter of panned targets and indicators on a substantial number of issues, hence the inability to report accordingly on matters such as HIVIAIDS. Key statistics and existing calculations such as HIV tests performed, anti-retroviral distribution patterns, acute malnutrition child fatality and maternal mortality in facility ratio, were evident (Gauteng Health Department, 2018:146-147).

The report is a direct attack on structures, systems and processes associated with key financial, supply chain management and procurement, risk management, internal audit and monitoring and evaluation, showing them to be incapable of validating their data and audit evidence regarding targets, variance, adjustments and achievements. This meant that there were no concrete reports and evidence for achievements reported and mentioned in the Department's financial report (Gauteng Health Department, 2018:147).

These findings are a direct indictment against the existing Department/Section performing monitoring and evaluation in the entity, as the findings indicate that there is no connection of outputs and outcomes of expected achievements of planned targets and that there is inconsistency or non-existence of information on this key issue. The expanded critique of the Auditor General towards the Gauteng Department of Health and its Monitoring and Evaluation departmental mechanisms encapsulated a number of violations of the Public Finance Management Act, especially section 40(1) (b), dealing with statements related to assets, liabilities, goods and services, immovable assets, workin-progress, and contingent liabilities identified in the process of the auditing exercise (Gauteng Health Department, 2018:147-148).

As in all previous years, the Department was mentioned as a serial violator of National Treasury regulation in terms of supply chain as treasury regulations $16 \mathrm{~A} 6.1$ and $16 \mathrm{~A} 6.4$. The process of dealing with transaction values below and above R500 000 have been perpetually violated as in all previous years (Gauteng Health Department, 2018:149).

The existing internal control deficiencies identified in the report are also critical of the functions of monitoring and evaluation as well as the leadership of the accounting officer who along with the department, did not perform the expected and necessary oversight responsibility with regard to contract management and procurement, as well as the preparation of the annual reports such as the performance management and financial statements. These realities resulted in a perpetual violation of important laws, rules and regulations that led to a number of investigations of fraud, theft, negligence and procurement irregularities, which were finalised by the Special Investigating Unit (SIU) and the Department itself (Gauteng Health Department, 2018:149-150).

\section{THE CASE STUDY}

There have been a number of corruption cases in the Department that would have made frontpage 
headlines throughout the world, not only because of the R1.2 billion corrupt expenditure and fraud total, but for a number of other reasons. This raised the debt of the Department to R6 billion in 2018 (Dlamini, 2018).

The SIU investigation was authorised by a presidential proclamation issued in 2010. The final report was only handed to President Zuma in March 2017. It became public under President Ramaphosa, and took seven years to complete (Scribd, 2017).

Key reasons found for the looting were 'gross financial mismanagement', and the 'collaboration' of senior officials with private sector entities operating during the $2008-2009$ period. The private company, a protagonist in the relationship, was irregularly hired to guide the department's spending and operational patterns but did not perform its responsibilities in the budget allocation determination. It charged exorbitantly inflated prices for goods and services, billed for work never performed, and double-billed for work done. It manipulated contracts for work and conferences and flew a politician to Cape Town, Vienna, Lusaka, London, Durban, Mauritius and Dubai twice (Business Day, 2018). The company's fraudulent acts included contracts to friends and relatives, inflating prices, receiving payments before approval of projects, appointing other companies or service providers without the knowledge of the department, and receiving kick-backs from sub-contractors. Following the SIU's call for criminal prosecutions against the key protagonists named in the report, the corrupt consultancy firm went bankrupt (Dlamini, 2018).

This massive fraud case is open to a number of serious political, administrative and organisational questions directly related to the theme of monitoring, evaluation and accountability. This is because the tornado-like incidents of fraud and corruption constitute perpetual acts of financial misconduct founded on the supply chain management and procurement section of the Department.

Given the strict legislation, and Treasury and Auditor General rules and regulations regarding issues of procurement of goods and service, the process followed by the department never stopped, but in fact opened up the doors to corruption acts facilitated by senior politicians and administrators who colluded with private sector operators.

The fact that a number of senior administrators were lightly penalised after short disciplinary hearings while others were allowed to resign without sanctions, is a clear sign of an immunity-driven collusion. Neither M\&E operators nor audit committee member/s or risk management practitioners paid homage to accountability towards managers, leaders, politicians or citizens, when 20 staff members from the consulting company were seconded to crucial decision-making positions with the provincial Department of Health. One of them was seconded as a senior financial officer whose key duties were related to the approval of payments to his own consulting firm. He also served as a voting member of the department's council of acquisitions (Scribd, 2017).

\section{THE INTERVIEWEE RESPONSES}

Differences and similarities of opinion amongst the 15 interviewees belonging to the whole health spectrum in the province were noted.

There was a general agreement in response to the question on the problems facing $M \& E$ in the department.

The key issue identified was the 'non-alignment of the existing M\&E framework with the Departmental strategic plan'. Two of the Department's employees indicated that in the monitoring process, the expected indicators were difficult to identify and this made the data following processes difficult. This problem was seen as endemic in the monitoring stage because there were serious problems inside the M\&E Coordinating Unit that is responsible for streamlining the operating systems that are fundamental for producing the information sets and frameworks for measuring performance (Interviewees 2, 4, 7 and 12).

It became evident that a key difficulty in terms of these M\&E processes was the diversification of service delivery levels associated with the Health Department. This because of the existence of 6 District Offices and 25 sub-district health facilities. What this means, is that the cooperation, management, coordination and creation of standardised systems, structures and processes is complicated. All these offices report directly to the Head Office $(1,5,6,11$ and 15).

It was stated that the main problem in terms of compiling the M\&E reports lies in the fact that it is only the District Offices that collect the data and are responsible for their credibility, through the collection, analysis, verification and interpretation processes. This data information reaches the District Offices via the Sub-District Offices. It was felt that due to staff capacitv 
gaps and weaknesses in the latter, the collection, collation, analysis and verification were on occasion not up to the expected high standards (Interviewees 3, 5, $6,9,11$ and 15).

This created problems in the process of data flow as there were often instances of data delays, lack of appropriate verification, notable gaps and confusing sources of information. This made data management very difficult, especially due to skills capacity gaps (1, 4, 6, 9 and 15).

There was a feeling that the 'data distribution' from District Offices quarterly to Head Offices for verification before they reached the Head of Department and then the Provincial Minister (MEC), was unnecessarily bureaucratic and there were perpetual problems and challenges such as major delays in between destinations, and lack of scientific and comprehensive verification $(2,4,7,10$ and 13$)$.

There was an opinion that the monthly data capturing by project managers in the monitoring phases posed problems because on occasion there was a lack of comparative analysis of operational plans and simultaneous reporting, that led to unsatisfactory monitoring of quarterly results. This reality created serious gaps in the 5-year review evaluation and the mid-term reviews, as there was always need of periodic external and internal evaluations that do not take place for a number of reasons. This means that there is a lack of data instrumental in the development of adequate terms of reference, procurement and management services (Interviewees 1, 3, 5, 7, 11 and 14).

In response to the question relating to whether existing systems have been able to detect and prevent corruption in the M\&E systems, there was also evidence of agreement mixed with a certain lack of understanding on the part of interviewees, of existing dynamics and relations of the systems with vital operations such as internal audit and risk management functions.

Overall, there was a wide-ranging feeling that key strategic plans were not taken into account in the operational systems terrain for a number of reasons. The same feelings were evident in the responses recorded in relation to the previous question in more concrete terms (Interviewees 2, 4, 6, 9, 12 and 15).

There was an agreement that M\&E systems are not isolated from, but directly or indirectly connected to, a number of important systems and processes such as internal audit controls and in cases where these operational systems were dysfunctional, the repercussions were evident in M\&E. The feeling was that such systems were the foundation of accountability and their dysfunction or malfunction opened the doors for corrupt official, politicians, and mediators of companies. This was the key issue described as the existences of a large number of District Offices, and un-coordinated management at all levels made the system difficult to operate. The 'excessive number of service delivery points' exacerbated the problems, it was said, because it complicated the work performance (Interviewees 1, 2, 4, 6, 9, 11, 12 and 15).

It was accepted that such problems have been perpetually debated over the years and were well known to the National Department of Health that has tried a number of tactical and strategic interventions to improve the situation without tangible results. It was repeatedly stated that given such circumstances, the dream of the National Health Insurance (NHI) will be a major nightmare for both government and the people (Interviewees 1, 3 6, 7 9, 10, 13 and 15).

There has been a belief that the fact that M\&E functions and systems have been institutionalised within the organizational structure of the Department, could be key to improving the performance levels, value systems, accountability and culture of personnel, resulting in serious advantages of organisational patterns, structures standards, processes and individual and group performance (Interviewees 4, 6, 11,13 and 14).

Answering the question whether such changes have been beneficial for service excellence, and the fight against corruption and accountability, there was firstly a general belief that the appointment of more than ten officials including Directors, Deputy Directors and Assistant Directors, was a step forward. However secondly, the fact that all of them were based at the

Head Office, while there were three regional coordinators in the three health regions undertaking key M\&E functions, was seen as creating a number of serious problems and challenges (Interviewees 2, 5, 7, 9 and 13).

Interviewees with intimate knowledge of the situation indicated that the appointments had created, at least initially a feeling of revitalisation of functions and operations, and an upsurge in accountability 
because the key function was recognised as such. However, as the process unfolded, it became evident that the expected outcomes at a number of levels were not forthcoming. The most vital of all was that the expected balance between planned and the actual reported targets never occurred. It was said that this was evident at almost all functional levels because of challenges associated with coordination, information weaknesses, human resources challenges, infrastructure, citizen's mistrust and lack of participation (Interviewees 1, 3, 6, 812 and 15).

It was said that there was a wide acknowledgement at all government and governance layers that there were serious challenges both in the planning and implementation of building a successful and compliant department that is built on accountability, which took a stand in the fight against corruption and the success of its professional mission. This has been also blamed on the lack of budget allocation for the recruitment, training of new and existing staff, and lack of support and development of the existing information systems (Interviewees 1, 2, 4, 6, 9 and 12).

A range of opinions were expressed in response to the question 'Do the staff operating these systems have the knowledge, experience and accountability attitudes to operate them?'

There was a belief amongst a number of respondents that on many occasions, there was an adequate number of civil servants who had the capacity, experience and knowledge to operate such systems efficiently, but it was noted that the existence of 'operational gaps, political realities, relations and power struggles', provided opportunities for corruption. The gaps mentioned were the result of weaknesses of existing rules and regulations or systemic weaknesses in other sections of the entity (Interviewees 3, 5, 11, and 15).

The political power struggles over opportunities for corruption, it was stated time and again, have been at the centre of most corruption taking place throughout the years, because it was extremely difficult for administrators at all levels to put a stop greed and avarice. Such behaviour was the founded on the individual or collective lack of ethics at all levels of the political and administrative levels of the Department (Interviewees 1, 2, 5, 7 and 15).

There was also a position that given the weaknesses in the existing systems and M\&E processes, there have been cases of knowledgeable and skilled employees who have taken advantages of gaps and weaknesses in order to commit fraudulent acts, knowing that even in cases where they were liable to be caught, the existing conditions within the Department almost guaranteed immunity even after a disciplinary process (Interviewees 2, 6, 7, 10, 11, 13 and 15).

There was a difference in opinion regarding the frequency of 'individual fraud' versus 'syndicate fraud' operated by small groups within specific departments. It was acknowledged in general that such realities could not be identified singularly by M\&E, but only through cooperation with other sections/departments, such as internal audit or supply chain and procurement (1, 3, 4 and 12).

However, in such cases, the question remains as to how structures, systems and processes that produce pre-determined outcomes and operate 'under surveillance', can allow such acts to take place. This means that the surveillance in such cases mean very little, as there is a complete absence of thorough assessment, continuous observation and direction, as well as monitoring and evaluation of the section head/s and their regional counterparts.

Response from a number of interviewees pinpointed the influence of section leadership, not only in the M\&E operations but within the whole spectrum of the organisational terrain. It is believed that leaders with ethical and professional attitudes and behaviour play a key role in transparent and accountable actions, planning and implementation. Inevitably, leaders who are 'captured' as perpetrators of corrupt acts cannot operate 'freely' unless they 'capture' the whole operational section (Interviewees 2, 4, 7, 9, 11 and 13).

In response to the question on the best ways to utilise M\&E in order to stop suppliers and service providers from getting involved in public corruption, a number of points are worth noting. There was a belief that although there were difficulties at present to monitor and corruption, according to the wide variety of anti-corruption legislation, rules and regulations the key issues were related to serious implementation challenges, because of weak and irregular coordination .The difficulty of the task increases on many occasions, according to respondents, because of two main reasons, the first the experience and political connections of private sector companies and syndicates and secondly the latter's experience in 
corrupt operations throughout the public sector spectrum, the variety of operational terrains and direct and indirect contacts with the 'appropriate' mediators (Interviewees 1, 4, 6, 9 and 13).

There was a visible lack of belief on the part of the respondents that the state possessed the appropriate attitude towards corruption not only in the Gauteng Health Department but throughout the public sector entities in the country (Interviewees 2, 4, 7, 10, 11 and 14).

These realities in fact prompted a number of the respondents expressing strong feelings that a number of existing laws, rules and regulations needed amendments, especially in relation to punishment for corrupt acts and perpetrators, meaning that those caught for corruption need to be punished and should not escape the rule of law (Interviewees 3, 5, 8, 9, 13 and 15).

It is evident that a Results-based system Monitoring and Evaluation System (RBM\&E) that is the demonstration of government effectiveness in terms of achieving a number of goals set in terms of performance management (Naidoo and Simmonds 2007 ) is absent. This means that the tracking of progress in terms of policy, programmes, and projects implementation becomes extremely difficult in terms of a greater focus on outcomes and impact (Kusek and Rist 2001:1).

A number of responses indicated a lack of integration of M\&E (in the context of RBM\&E) with the strategic plans of the Department. This means that M\&E and strategic planning work in silos. The principle that strategic plans need to be monitored and evaluated immediately (SAMEA 2013) is ignored.

Given the fact that M\&E is a strategic function and it can only be successful when it works plans the evidence that there no collaboration between key staff in a number of departments leads to the conclusion that adaptation and customisation are non -existent.

The challenge faced by the public servants in the $\mathrm{GDOH}$ associated with the fact that there is a serious problem of lack of capacity on M\&E and especially the evaluation component lead to the serious problem of serious dependency on consultants (SAMEA 2013).

It is important for all public entities, especially those in chronic problems and challenges such as the $\mathrm{GDOH}$, to follow the RBM\&E principle of starting the process with a problem identification. The responses indicated that the roots of the functionalities of the various programs are solution-driven and lacking a situational and feasibility perspective. (SAMEA 2013)

Table 1: The Latest Evidence-Based Corruption Index of the Gauteng Health Department 2013-2018

\begin{tabular}{|c|c|c|}
\hline Corruption Type & Figures & $\begin{array}{c}\text { Comments } \\
\text { (where } \\
\text { applicable) }\end{array}$ \\
\hline \hline Theft & $291(21)$ & \\
\hline Absenteeism & $196(18.9 \%)$ & \\
\hline Fraud & $198(19.1 \%)$ & \\
\hline Absent Without Leave & $56(5.4 \%)$ & \\
\hline Insubordination & $44(4.2 \%)$ & \\
\hline Negligence & $44(4.2 \%)$ & \\
\hline $\begin{array}{c}\text { Supply Chain and Procurement } \\
\text { Fraud }\end{array}$ & $68(6.5 \%)$ & \\
\hline $\begin{array}{c}\text { Falsification of Records and } \\
\text { Offering Jobs for Cash (Bribery) }\end{array}$ & $136(13.1 \%)$ & \\
\hline Desertion of Post & $26(2.5 \%)$ & \\
\hline $\begin{array}{c}\text { Misappropriation of } \\
\text { Departmental Property }\end{array}$ & $21(2.0 \%)$ & \\
\hline $\begin{array}{c}\text { Total of corruption acts } \\
\text { Dent }\end{array}$ & 1036 & \\
\hline
\end{tabular}

\section{CONCLUSIONS}

Evidence-based policy is the cornerstone of attaining desired results. This means that a comprehensive, accountable and effective M\&E system is its foundation. The vitality of M\&E rests primarily on its compliance dimension, ensuring that the state institutions comply with the legal parameters, norms and standards. M\&E, when performed in an accountable and efficient pattern, is crucial in the fight against corruption and a foundation of honest and effective service delivery.

The realities uncovered have shown conclusively that these M\&E fundamentals have been absent from the Gauteng Department of Health, hence the dire consequences for everyone, especially the poor and marginalised.

There are a number of lessons learnt from this empirical exercise and through the study of both the theories and practical planning and implementation of this process.

The Gauteng experience has shown that a number of existing laws, rules and regulations need 
amendments, especially in relation to punishment for corrupt acts and perpetrators, meaning that those caught for corruption need to be punished and should not escape the rule of law.

It has been shown that the only way to stop the corrupt providers from committing acts of corruption is to appoint incorruptible, honest, transparent and accountable people at the leadership and management levels of all departments, sections and social delivery points in the state. It was admitted that such an eventuality was extremely difficult, if not impossible.

Critical to such practices is ensuring that is that professional, knowledgeable and technically advanced M\&E capacity is built throughout the state spectrum. Even if is achieved, it will be weak if effective coordination systems integrated at all state levels do not exist

Political interference and influence are forbidden in the quest for ensuring that the M\&E systems and processes have integrity and are accountable only to the country's people. The establishment of a revamped legal framework emphasising the transparency dimensions of the structures and processes will be instrumental in increasing accountability. A careful study of relevant literature in Ethiopia and Rwanda and the key issue of citizen participation could be useful for South Africa, and Gauteng's Department of Healthcare. The empowerment of all staff and managers, including the service delivery staff, throughout the professional spectrum, is an urgent necessity.

It is evident that the absence or very limited planning and implementation of a Results-based system Monitoring and Evaluation System (RBM\&E) leads to serious difficulties in the tracking of progress in terms of policy, programmes, and projects implementation.

The lack of integration of M\&E with the strategic plans of the Department and the absence of collaboration between key staff in a number of departments leads to the conclusion that adaptation and customisation are seriously weakened. This trend is worsened by the fact of capacity gaps that exists and leads to perpetual; dependency on consultants.

The lack of problem identification a foundation stone in the conceptualisation, planning and implementing the RBM\&E principles lead to the absence of solutiondriven outcomes.
Adopting indigenous African approaches is the key to the future of monitoring and evaluation as a structure, and any process that does not take into account the culture, history, beliefs and context; this is not only against the African Agenda 2063, but also the expectation of our country's people.

\section{REFERENCES}

Bamberger, M., Rugh, J. \& Mabry, L. 2011. Real world evaluation: Working under budget, time, data, and political constraints, New York: Sage, Thousand Oaks.

Bamberger, M., Vaessen, J. \& Raimondo, E. (eds.). 2015. Dealing with complexity in development evaluation: A practical approach, New York: Sage, Thousand Oaks. https://doi.org/10.4135/9781483399935

Bryman, A. \& Bell, E., 2007. Business Research Methods. 2nd Ed. New York: Oxford University Press.

Business Day. 2018. Report details Deceit under Brian Hlongwa watch as Gauteng Health MEC https://www.businesslive.co.za/bd/national/health/2018-0621-report-details-deceit-under-brian-hlongwas-watch-asgauteng-health-mec/

Center for Global Development. 2009. US Spending in Haiti: The Need for Greater Transparency and Accountability. http://www.cgdev.org/doc/full_text/CGDBriefs/1426965/USSpending-in-Haiti-The-Need-for-Greater-Transparency-andAccountability.html

Charmaz K 2001 Qualitative interviewing and grounded theory analysis .In Gabrium G.F and Holstein J.A. Handbook of Interview Research, Thousand Oaks, Cal. Sage Publications

Child, K. 2018. 'How Gauteng Health Department was plundered' June 21. https://www.timeslive.co.za/news/south-africa/201806-21-how-gauteng-health-department-was-plundered/

Dlamini, P. 2018. Gauteng health department says it's dealing with its debt, TimesLive June 29. https://www.timeslive. co.za/politics/2018-06-29-gauteng-health-department-saysits-dealing-with-its-debt/

Feldman, M.S. \& Pentland, B.T. 2003. 'Reconceptualizing organizational routines as a source of flexibility and change', Administrative Science Quarterly 48(1), 94-118. https://doi.org/10.2307/3556620

Gauteng Planning Commission. 2012. Gauteng Evaluation Frame and Provincial Evaluation Plan for the Period 2012/2013 to 2015/2016. Johannesburg.

Gauteng Department of Health, 2010. Monitoring and evaluation framework. Johannesburg: Gauteng Department of Health.

Gauteng Planning Commission. 2012. Gauteng Evaluation Frame and Provincial Evaluation Plan for the Period 2012/2013 to 2015/2016. Johannesburg.

GWM\&ES. 2007. Policy Framework for a Government-wide Monitoring and Evaluation System, Pretoria: Government Printers

Jankowich, A.D. 2005. Business research projects. 4th ed. London, UK: Thomson Learning.

Kimberly, A. 2002. The Content Analysis Guidebook. Thousand Oaks, CA: Sage.

Krippendorff, K. 2004. Content Analysis: An Introduction to Its Methodology (2nd Ed.). Thousand Oaks, CA: Sage.

Kusek, J.Z. \& Rist, R.C., 2004, Ten steps to a results-based monitoring and evaluation system: A handbook for development practitioners, Washington DC: World Bank Publications.

Mouth, J. 2010. Questionnaire construction: A guide, New York: Longmans. 
Nachmias, C. F. and Nachmias, D. 2008. Research methods in the social sciences.(7th ed.), New York: Worth Publishers.

Naidoo, K and Simmonds, S. (2007). Paper for Public Service Commission Internal Human Resource Conference: Some reflections on public sector performancehttp://www.google.co.za/\#site $=\&$ source $=h p \& q=s$ ome+reflections+in+public+sector+performance $\% 2 \mathrm{C}+$ Naidoo \&oq=some+reflections+in+public+sector+performance $\% 2 \mathrm{C}+$ Naidoo\&gs_I=hp.3...38841.68965.0.69465.57.34.1.6.6.1.624 $3760.22 \mathrm{j} 1 \mathrm{j} 4 \mathrm{j} 2.9 .0 \ldots 0.0 \ldots$..1c.1.9.hp.0rjl8e8aV0M\&bav=on.2,or. \&bvm=bv.45373924,d.d2k\&fp=7e844e21cf03e5e1\&biw $=109$ $3 \&$ bih=422.. [Accessed 2017-086-02.

National Department of Health. 2011. District Health Management Information System. Pretoria: National Department of Health.

National Treasury. 2007. Framework for Managing Programme Performance Information, The National Treasury.

Neuman, W.L. 2003. Social research methods: qualitative and quantitative approaches. (5th ed.) Boston: Allyn \& Bacon.

Patton, M.Q. 2011, Developmental evaluation: Applying complexity concepts to enhance innovation and use, New York: Guilford Press,

Powell, W.W. \& DiMaggio, P.J. 2012. The new institutionalism in organizational analysis, Chicago: University of Chicago Press.

Presidency. 2009. Policy Framework for a Government-wide Monitoring and Evaluation NEPF 2011. National Evaluation Policy Framework, Pretoria: Government Printers.

Republic of South Africa. 1997. The White Paper on Transforming Public Service Delivery (Batho Pele White Paper). Pretoria: Government Printers.

Republic of South Africa. 1999. Public Finance Management Act, 1999 (Act 1 of 1999) Pretoria: National Printers.

Republic of South Africa. 2007. Policy Framework on GovernmentWide Monitoring and Evaluation System. Pretoria: Government Printers.
Republic of South Africa. 2011. National Evaluation Policy Framework. Government Printers: Pretoria.

SAMEA. 2013. 4th Biannual SAMEA Conference: September Conference Materials. http://www.samea.org.za/index.php? module=pagesetter \&type $=$ user\&func $=$ viewpub\&tid $=4 \&$ pid-59

Saunders, D. and Mark, E. 2007. Research Methods: An Advanced Guide, N.Y.: Wardswoths.

Scribd 2017. Report on Proclamation 21 of 2010. https://www.scribd.com/document/382254909/SIU-Reporton-Proclamation-R21-of-2010\#from_embed

Silverman, D. 2005. Doing qualitative research. A practical handbook. Thousand Oaks: Sage.

Stemler, S. 2001. An Overview of Content Analysis Practical Research and Evaluation 7(17):112-128.

Tarsilla, M. 2014. 'Evaluation capacity development in Africa: Current landscape of international partners' initiatives, lessons learned and the way forward', African Evaluation Journal, 2(1), 1-13. https://doi.org/10.4102/aej.v2i1.89

United Nations Development Programme Evaluation Office. 2009. Handbook on Monitoring and Evaluating for Results. http://web.undp.org/evaluation/documents/handbook/mehandbook.pdf

\section{INTERVIEWS}

Interviewees 1 to 7: Public Sector Senior and Middle Managers Interviewees 8 to 10: Academics and Researchers Interviewees 11 to 14: Private Sector Professionals Interviewee 15: Senior Politician

Received on 30-04-2019 Accepted on 01-06-2019

Published on 07-08-2019

DOI: https://doi.org/10.6000/1929-7092.2019.08.45

(C) 2019 Mantzaris and Pillay; Licensee Lifescience Global.

This is an open access article licensed under the terms of the Creative Commons Attribution Non-Commercial License (http://creativecommons.org/licenses/by-nc/3.0/) which permits unrestricted, non-commercial use, distribution and reproduction in any medium, provided the work is properly cited. 